\title{
Cross-linked Polyvinyl Alcohol Films as Alkaline Battery Separators
}

Dean W. Sheibley, Michelle A. Manzo, and Olga D. Gonzalez-Sanabria Lewis Research Center Cleveland, Ohio

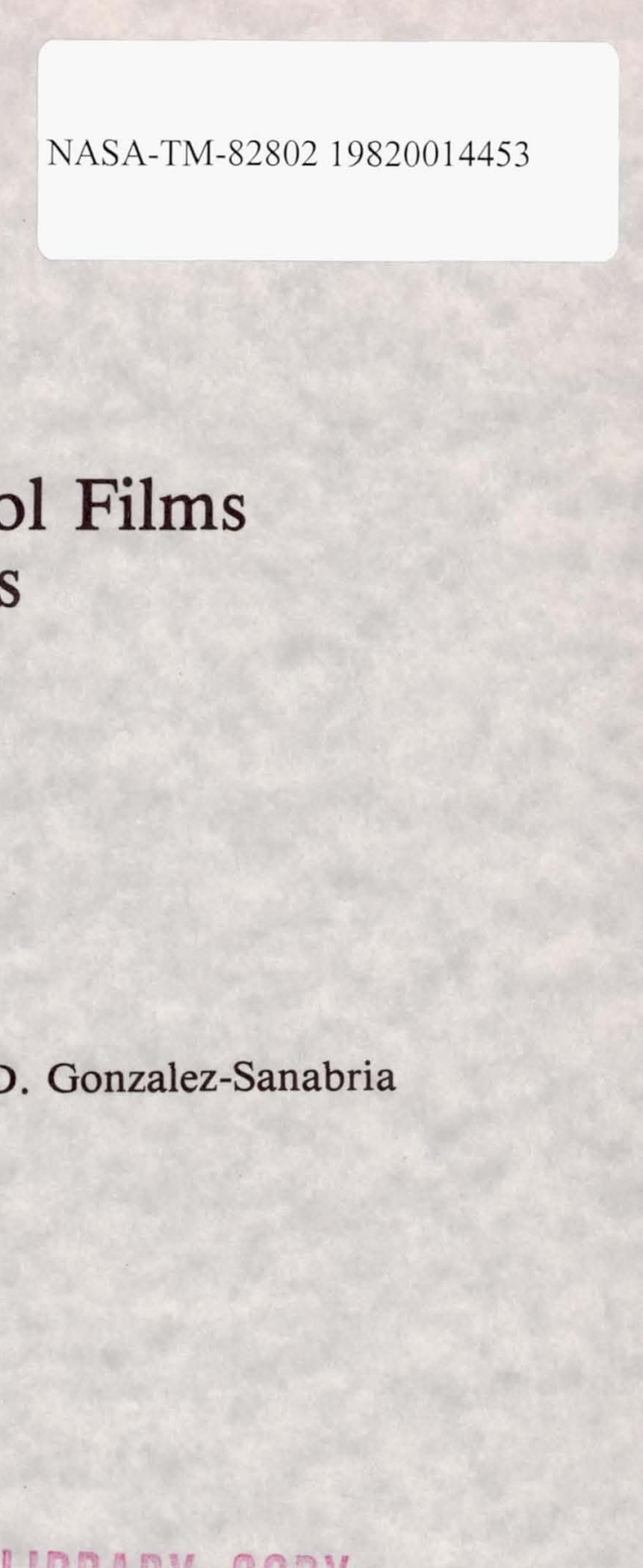

March 1982
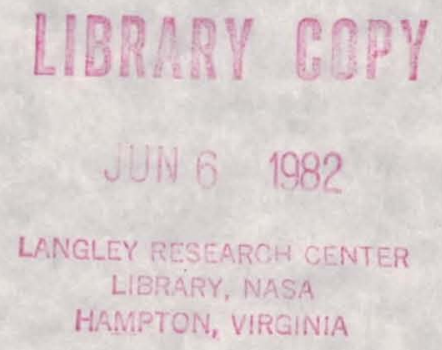
Trade names or manufacturers' names are used in this report for identification only. This usage does not constitute an of ficial endorsement, either expressed or implied, by the National Aeronautics and Space Administration. 


\section{CROSS-LINKED POLYVINYL ALCOHOL FILMS}

\section{AS ALKALINE BATTERY SEPARATORS*}

Dean W. Sheibley ${ }^{\dagger}$, Michelle A. Manzo, and 0lga D. Gonzalez-Sanabria

National Aeronautics and Space Administration

Lewis Research Center

Cleveland, Ohio

\section{SUMMARY}

Cross-linking methods have been investigated to determine their effect on the performance of polyvinyl alcohol (PVA) films as alkaline battery separators. The following types of cross-linked PVA films are discussed: (1) PVAdialdehyde blends post-treated with an acid or acid periodate solution (twostep method), (2) PVA-dialdehyde blends cross-linked during film formation (drying) by using a reagent with both aldehyde and acid functionality (onestep method). Laboratory samples of each cross-linked type of film were prepared and evaluated in standard separator screening tests. Then pilot-plant batches of films were prepared and compared to measure differences due to the cross-linking method. The pilot-plant materials were then tested in nickel oxide - zinc cells to compare the two methods with respect to performance characteristics and cycle life. Cell test results are compared with those from tests with Celgard.

\footnotetext{
*Part of this paper was presented at the 158th Meeting of the Electrochemical Society, Hollywood, Fla., Oct. 5-10, 1980; Abstract 95.

${ }^{\dagger}$ Electrochemical Society Active Member.

Key-descriptors: Alkaline batteries; Separators; Cross-linked polyvinyl alcohol; Nickel oxide - zinc cells.
} 


\section{INTRODUCTION}

The use of polyvinyl alcohol (PVA) as a separator in various alkaline battery applications is well known. PVA film separators are used because of their insolubility and high ionic conductivity in alkaline electrolytes. Further, PVA film is easily fabricated on a commercial scale from aqueous solution and presents neither a health hazard to personnel nor a pollution threat to the environment.

Cross-linking PVA makes it water insoluble, increases its mechanical strength, and improves its oxidation resistance (ref. 1). Methods of crosslinking PVA have been reported by Philipp and Hsu (ref. 2) with applications for use in alkaline electrolytes. More recently, low-molecular-weight PVA films cross-linked by using dialdehydes, aldehydes with acid functional groups, and polysaccharides (aldehyde precursors) were evaulated as alkaline battery separators by Hsu and Sheibley (ref. 3). This work showed that cross-linked PVA films exhibit acceptable properties in comparative separator screening tests and perform in an acceptable manner as separators in silver oxide - zinc $(\mathrm{Ag}-\mathrm{Zn})$ and nickel oxide - zinc $(\mathrm{Ni}-\mathrm{Zn})$ cells from the standpoints of cycle life and cell performance.

This paper compares the effect of two cross-linking methods on PVA film properties measured for alkaline battery separators. One cross-linking method involves a two-step process: First, the film is made; then the dry film is treated with acidic solutions to achieve the desired cross-linking. The second method is a one-step method developed at the NASA Lewis Research Center to cross-link PVA films during commercial production operations. The PVA film is cross-linked during conventional oven drying; thus no further treatment is required. 
Separator properties were measured for films made by the two-step method where the cross-linking reaction is catalyzed by either acid or acid periodate solutions. Two dialdehyde cross-linking reagents were compared. Then the effect on separator properties of glyoxylic acid (the reagent used to convert the two-step method into a one-step method) was evaluated in both methods.

Finally films made on pilot-plant equipment were evaluated to measure the effect of the two cross-linking methods on separator properties. These films were then performance characterized and cycle tested in small $\mathrm{Ni}-\mathrm{Zn}$ cells to compare the two cross-linking methods and to compare the cross-linked PVA films to Celgard.

\section{MATERIALS AND PROCEDURE}

\section{Materials}

A commercially available polyvinyl alcohol (PVA), Elvanol 71-30, a mediumviscosity-grade PVA, was used for this work. This material is greater than 99 percent hydrolyzed. A 4 percent aqueous solution has a viscosity of 28 to $32 \mathrm{cP}$. The 1,2 diol content was 3.99 groups per 100 monomer units.

The furan 2,5-dialdehyde (DAF) was supplied by Quaker Oats Chemical Co. The terephthaldehyde (TPA) was obtained from Fisher Scientific. The structural formulas of DAF and TPA are shown in table I. The glyoxylic acid (GOA) also came from Fisher (a 50 percent solution in water). The structural formula of GOA is shown in table II. The sucrose was cane sugar. The filler materials, shown in table III, came from commercial sources. The (143) filler combination was 7.9 vol \% $\mathrm{SiO}_{2}$ (Cab-0-Sil M, Cabot Corp.) and 92.1 vol \% 200mesh white pine wood flour (Wood Flour, Inc.). The (144) filler combination was 7.8 vol $\% \mathrm{SiO}_{2}$ and 92.2 vol \% calcium zirconium silicate (TAM Products, 
Hightstown, N.J.). The acid cross-linking solution contained 20 milliliters of concentrated $\mathrm{H}_{2} \mathrm{SO}_{4}$ and $200 \mathrm{~g}$ of $\mathrm{Na}_{2} \mathrm{SO}_{4}$ dissolved in 1 liter of water. The acid periodate solution contained $30 \mathrm{~g}$ of $\mathrm{KIO}_{4}, 50$ milliliters of concentrated $\mathrm{H}_{2} \mathrm{SO}_{4}$, and $200 \mathrm{~g}$ of $\mathrm{Na}_{2} \mathrm{SO}_{4}$ dissolved in 1 liter of water.

\section{General Procedure for Preparation of Aldehyde Cross-linked}

PVA Membrane Separators

Two-step cross-linking method. - A quantity of the dialdehyde or aldehyde precursor is added to an aqueous solution of 10 wt \% Elvanol 71-30 in order to achieve the theoretical amount ${ }^{1}$ of cross-linking desired (usually 2 to 10 percent cross-linker). The solution is well mixed. Entrapped air bubbles are removed by placing the solution in a bell jar under a vacuum. The solution is cast on a smooth, clean, glass plate by using a Gardner blade. The cast film is air dried at room temperature, usually overnight. For films with the dialdehyde cross-linking reagent, cross-linking is achieved by immersing the dry film in a solution of sulfuric acid ( $\mathrm{pH}, 4$ to 5 ) saturated with sodium sulfate and then gradually increasing the temperature to $90^{\circ} \mathrm{C}$ over a period of 4 to $16 \mathrm{hr}$. The films are then rinsed in water to remove the sodium sulfate. The treated film is immersed in boiling water; if it is cross-linked, it will not dissolve. This is a qualitative test for cross-linking.

${ }^{1}$ The theoretical amount of cross-linker desired is the percentage of cross-linking reagent required to chemically react with all the hydroxyl groups present in the PVA; e.g., 2 percent cross-linking would be 0.02 times the amount required to react with 100 percent of the PVA hydroxyl groups, assuming one aldehyde group per two hydroxyl groups. 
For films containing an aldehyde precursor (e.g., polysaccharides) or where cleavage of the 1,2-diol units of the PVA is desired, cross-linking is achieved by immersing the $\mathrm{film}$ in the acid periodate solution ( $\mathrm{pH}, 4$ to 5 ). The same heat-treatment and rinsing step and the boiling water test for cross-linking are performed on the film.

One-step cross-linking method. - A quantity of dialdehyde is added to an aqueous solution of 10 wt \% Elvanol 71-30 in order to achieve the theoretical amount of cross-linking desired, and the solution is well mixed. Then, a quantity of acid-aldehyde reagent, glyoxylic acid, is added to attain the theoretical amount of reaction desired, and the solution is well mixed. The amount added is sufficient to produce a pH value below 5 . The entrapped air bubbles are removed by vacuum. The film is then cast on a clean, smooth, glass plate by using a Gardner blade. The film is cast before the mixture begins to gel. At a solution temperature of $120^{\circ} \mathrm{F}$, gelation starts about 45 min after addition of the GOA. After the film is cast and air dried, the glass plate is placed in an oven for a period of time, the length of which depends on the drying temperature. Time ranges from $4 \mathrm{hr}$ at $90^{\circ} \mathrm{C}$ to $5 \mathrm{~min}$ at $160^{\circ} \mathrm{C}$. The film is placed in boiling water to check for cross-linking. Screening tests of cross-linked PVA separators. - The cross-linked PVA films were evaluated by determining their ionic resistivity (dc method), zinc dendrite penetration rate, and zincate ion diffusivity according to methods described in reference 4 .

Cel1 test evaluation of cross-linked PVA separators. - Cell test evaluation of the cross-linked PVA film separators was performed in nickel oxide zinc $(\mathrm{Ni}-\mathrm{Zn})$ cells of approximately 7.2-A-hr capacity. The electrolyte was 35 wt \% KOH. Ampere-hour efficiency reached 95 percent after three formation cycles. Overcharge was limited to 10 percent of the nominal capacity. 
The $\mathrm{Ni}-\mathrm{Zn}$ cell electrode configuration was $\mathrm{Ni}-\mathrm{Zn}-2 \mathrm{Ni}-\mathrm{Zn}-\mathrm{Ni}$. Electrode sizes were $7.3 \mathrm{~cm}$ by $9.4 \mathrm{~cm}$ with thickness ranging from $0.075 \mathrm{~cm}$ for the nickel electrode to $0.225 \mathrm{~cm}$ for the zinc oxide electrode. Performance was characerized at discharge rates of $\mathrm{C} / 8$ (the 8 -hr rate, the current required to discharge the cell capacity in $8 \mathrm{hr}$ ), C/4, C/2, C, and $2 \mathrm{C}$. Midpoint voltage (the voltage after $3.6 \mathrm{~A}-\mathrm{hr}$ of capacity was removed) was recorded as was the ampere-hour capacity above $1 \mathrm{~V}$.

Cycle testing consisted of $8-\mathrm{hr}$ cycles (6-hr of charge (C/12 rate) and 2 $\mathrm{hr}$ of discharge ( $\mathrm{C} / 4$ rate $))$. The discharge current density was approximately $7 \mathrm{~mA} / \mathrm{cm}^{2}$. The testing was continuous: three cycles per day, 7 days per week. Depth of discharge was 50 percent on the basis of the nominal 7.2-A-hr capacity.

\section{RESULTS AND DISCUSSION}

The two-step method of cross-linking PVA uses either an acid solution or an acid periodate solution. The acid solution is used when a dialdehyde is incorporated in the $f i l m$. The acid catalyzes the acetalization reaction and this leads to cross-linking. The acid periodate method is used to cross-link PVA under several conditions. It can be used to cross-link PVA alone through oxidative cleavage of its 1,2-diol units in order to form aldehyde groups that react with the secondary alcohol groups of PVA (ref. 1). The addition of aldehyde precursors (polysaccharides such as sucrose or alginic acid) to PVA requires the acid periodate treatment to cleave the saccharide ring structure, resulting in aldehyde formation and cross-linking of PVA (ref. 5). Dialdehydes can also be used in the acid periodate method.

The effects of the acid and acid periodate catalysis methods were compared in reference 3 for cross-linked PVA films made from low-viscosity PVA. 
Results indicated that periodate-treated PVA films exhibited higher ionic resistivity but longer cycle life in $\mathrm{Ag}-\mathrm{Zn}$ and $\mathrm{Ni}-\mathrm{Zn}$ cells than did acid-treated fi Tms.

\section{Two-Step Cross-Linking Methods}

Table I compares the two-step cross-linking method using either acid or acid periodate and two cross-linking reagents: furan 2,5-dialdehyde (DAF) and terephthaldehyde (TPA) in medium-viscosity PVA. Properties measured were volume resistivity, zinc dendrite penetration rate, and zincate diffusivity. The data show that resistivity is increased by use of acid periodate treatment. However, periodate treatment results in a longer time for zinc dendrite penetration and a lower zincate diffusion rate. Un-cross-linked PVA has generally higher values of resistivity and zinc dendrite penetration rate, but the unaltered PVA structure shows the lowest zincate diffusion rate. From these data it appears that the cross-linked films generally represent an improvement in PVA used as an alkaline separator. The structures of the DAF and TPA are shown beneath table I.

The data presented in table II show the effect of incorporating GOA into the PVA. The reagent contains both an aldehyde and a carboxylic acid group. The carboxylic acid group affects the resistivity and zincate diffusion. The reaction of the aldehyde with PVA can follow two routes: either form the cyclic acetal with PVA (the intramolecular reaction) and/or cross-link it (the intermolecular reaction). The films were cast with the solutions buffered to a $\mathrm{pH}$ of 7 with ammonia solution. The dry films were then treated with the acid periodate solution according to the method described in the procedure section. The extent of cross-linking as compared with cyclic acetal formation with the GOA is not known. The percentage of GOA shown in table II represents 
the percentage of the theoretical amount needed to cross-link all the $\mathrm{OH}$ groups on the PVA.

As the amount of GOA in the film increases, the volume resistivity decreases with a corresponding increase in zincate diffusion rate. Between 10 and 50 percent GOA, the resistivity is halved (24 ohm-cm to $13 \mathrm{ohm}-\mathrm{cm}$ ) while the zincate diffusion rate increases approximately 10 percent. The use of smaller amounts of GOA appears to represent a method of resistivity control with minimal change in zincate diffusion.

The effect of GOA on lowering resistivity is very pronounced in the data shown in table IV. The films contained 2 wt $\%$ sucrose in PVA with the amounts of GOA required to achieve the percentages of the theoretical amount to react with all the PVA. The film-casting solution was buffered with ammonia solution to a pH of 7 . The dry film was then treated with acid periodate solution to cross-link the PVA through the tetra aldehyde fragments resulting from oxidative cleavage of the sucrose ring structure (ref. 5). The resistivity is decreased significantly (approx 90 percent) over the range 10 to 35 percent GOA. However, zincate diffusivity increases approximately 20 times over the same range. But the zincate diffusivity does not approach the $2 \times 10^{-6}-\mathrm{mole} / \mathrm{cm}^{2}$ min value of commercially available film separators (ref. 6 ) until about 70 percent GOA in the film is reached.

\section{One-Step Cross-Linking Method}

The two-step methods of cross-linking were judged not commercially desirable because the dry films when immersed in the acid treatment solutions lost much of their strength. They tore easily when handled. The use of machine processing appeared very unlikely. An evaluation of a batch-processing method to achieve cross-linking showed that a wound roll of un-cross-linked PVA film 
required a layer of material to separate the layers of PVA film to permit penetration of the acid treating solution and to prevent "adhesion" of adjacent film layers of PVA because of the cross-linking reaction. Further, batch processing would lead to nonuniform cross-linking as a result of varying solution concentration and temperature.

An apparent manufacturing method was found when the one-step crosslinking method described in the procedure section was worked out. The GOA, selected as the model reagent, was used to convert the cross-linking method to a one-step film-manufacturing process. The GOA contains the necessary acid to catalyze the cross-linking reactions; and since GOA reacts chemically with PVA, it leaves no residual products in the film that need to be rinsed out. The only constraints on the film-casting process are time and temperature. The film has to be cast before gelation starts in order to prevent casting a film containing domains of cross-linked product. As temperature is lowered, the time to gelation increases.

The acid periodate cross-linking treatment does not appear easily adaptable to the one-step method. The oxidation-reduction reaction involving the hydroxyl and the periodate leaves an iodine reaction product in the membrane. This can be removed by rinsing with water but involves an additional treatment step. This approach was not pursued.

In table III the effect of the cross-linking methods (two step vs. one step) on resistivity and zincate diffusivity is measured for two cross-linking reagents (DAF and TPA) and on films with 2 wt $\%$ DAF and 5 wt $\%$ fillers. The one-step method generally results in a cross-linked film having a higher (but acceptable) resistivity and a lower zincate diffusion rate. 


\section{Evaluation of Pilot-Plant Materials}

Two pilot-plant batches of film materials were processed. The purpose was to establish the feasibility of the one-step method on a PVA-film-casting machine. The compositions of the two materials are shown in table $V$. The major difference in composition was the 13 wt \% GOA (manufacturer error, should have been $10 \%$ ) added to the one-step material to cross-link it during the drying process. The one-step material came off the line as a cross-linked product. The two-step material was processed and dried and subsequently cross-linked by using the acid treatment procedure.

The two cross-linked films were then compared. The data on the two-step film in table VI are quite similar to the 2-wt \%-DAF two-step data in table III. The area resistivity of $0.037 \mathrm{ohm}-\mathrm{cm}^{2}$ shown in table VI is quite close to the $0.04 \mathrm{ohm- \textrm {cm } ^ { 2 }}$ value for the laboratory-prepared sample. The $6.8 \times 10^{-7}$-mole/ $\mathrm{cm}^{2}$ min zincate diffusion values are identical. Comparing the measured separator properties of the PVA films in table VI shows no significant difference in properties when films are made on pilot-plant equipment. Table VI also contains measured properties of Celgard 3401 and Cellophane, which are commercially available alkaline battery separators. The PVA films exhibit lower resistivity values, lower zincate diffusion rates, and equivalent hydroxyl diffusion rates. The measured rate of water diffusion was approximately 50 percent higher in the one-step cross-linked PVA than in Celgard.

The two PVA films were compared with Celgard in cycle tests in 7.2-A-hr $\mathrm{Ni}-\mathrm{Zn}$ cells. The construction of these cells differed from that of the cells described in reference 7 in that the nickel electrodes were contained in an absorber bag of beater-treated, fuel-cell-grade asbestos (ref. 6), while the zinc electrodes each received two wraps of the film separator (the PVA or the Celgard). 
A plot of discharge voltage as a function of ampere-hour capacity is shown in figure 1 for the two types of cross-linked PVA films and Celgard. The ampere-hour capacity was measured to a $1-V$ cutoff. The $C / 2$ discharge rate was $3.6 \mathrm{~A}$ (approx $14-\mathrm{mA} / \mathrm{cm}^{2}$ current density) for a constant current discharge. An examination of figure 1 shows that although the ampere-hour capacities did not vary much for the cells, the PVA films showed a midpoint voltage that was approximately $50 \mathrm{mV}$ higher than that of the Celgard film. The plots in figure 1 were taken from cycle 6 , the $c / 2$ rate performance characterization cycle.

Results of cycle testing in Ni-Zn cells are shown in figure 2. The PVA film from the one-step method was cycle tested in cells built by two suppliers ( $A$ and $B$ ). The average (and standard deviation) of two cells built by supplier A was $117( \pm 4)$ cycles; the average of three cells from supplier B was $116( \pm 10)$ cycles. A combined $(A+B)$ average of $116( \pm 8)$ is shown in figure 2. The average cycle life for the two-step method was $108( \pm 4)$ cycles based on three cells from supplier A. The 80-cycle result for Celgard is based on one cell from supplier $A$.

From the results of performance characterization and cycle life tests in small $\mathrm{Ni}-\mathrm{Zn}$ cells, the one-step method of cross-linking provides essentially the same results as the two-step method. Hence it appears that cross-linked PVA film made on commercial production equipment has acceptable separator properties and performs at least as well as the commercially available separators to which it was compared. 


\section{CONCLUDING REMARKS}

The development work on cross-linked polyvinyl alcohol (PVA) films for use as alkaline battery separators has produced the following results:

1. Chemically cross-linked PVA films generally exhibited better separator properties and better cell performance than un-cross-linked PVA.

2. The introduction of carboxylate functional groups to the cross-linked film reduced resistivity and, when used in smaller amounts ( $<35$ percent theoretical), did not appear to alter other film properties significantly.

3. A one-step cross-linking method appears adaptable to the commercial PVA film production process.

4. Cross-linked films produced on pilot-plant equipment by the one-step method did not exhibit significant differences from films similarly made by a two-step process.

These films are now under further development by W. R. Grace \& Co., Columbia, Md., under a cost-sharing contract with NASA (Contract NAS 3-22223). Producing a cross-linked $f i l m$ in a one-step process during conventional film drying opens up other areas for separator development. An obvious approach would be to apply the separator directly to the electrode as a result of a multiple dipping operation, using drying steps between dipping steps to achieve a satisfactory, defect-free separator.

\section{REFERENCES}

1. W. H. Philipp, L. C. Hsu, and D. W. Sheibley, U.S. Pat. 4,154,912 (1979).

2. W. H. Philipp and L. C. Hsu, "Three Methods for In Situ Crosslinking of Polyvinyl Alcohol Films for Application as Ion-Conducting Membranes in Potassium Hydroxide Electrolyte", National Aeronautics and Space Administration, Washington, D.C., NASA TP-1407 (1979). 
3. L. C. Hsu and D. W. Sheibley, Paper 122, presented at The Electrochemical Society Meeting, Los Angeles, California , Oct. 14-19, 1979.

4. "Characteristics of Separators for Alkaline Silver 0xide - Zinc Secondary Batteries: Screening Methods," Air Force Aero Propulsion Lab, Air Force Systems Command, Wright-Patterson AFB, Ohio, Edited by J. E. Cooper and A. Fleischer (1964).

5. L. C. Hsu, D. W. Sheibley, and W. H. Philipp, U.S. Pat. 4,272,470 (1981).

6. D. W. Sheibley, M. A. Manzo, and 0. D. Gonzalez-Sanabria, Paper 96, presented at The Electrochemical Society Meeting, Hollywood, Florida, Oct. 5-10, 1980.

7. L. C. Hsu and D. W. Sheibley, "Inexpensive Crosslinked Polymeric Separators Made from Water Soluble Polymers," National Aeronautics and Space Administration, Washington, D.C., NASA TM-82619 (1979). 

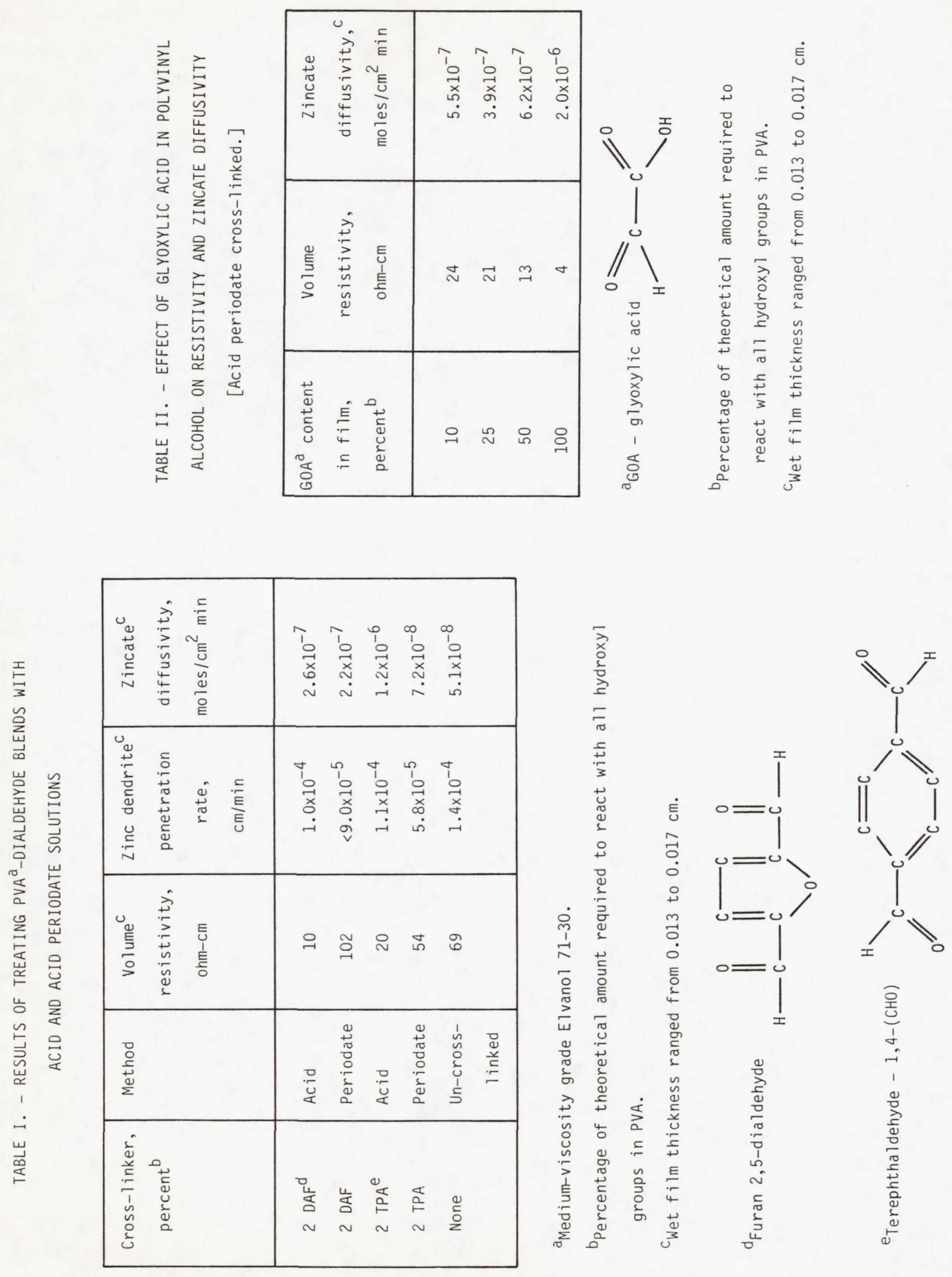
TABLE III. - COMPARISON OF FILMS MADE WITH TWO- AND

ONE-STEP CROSS-LINKING METHODS

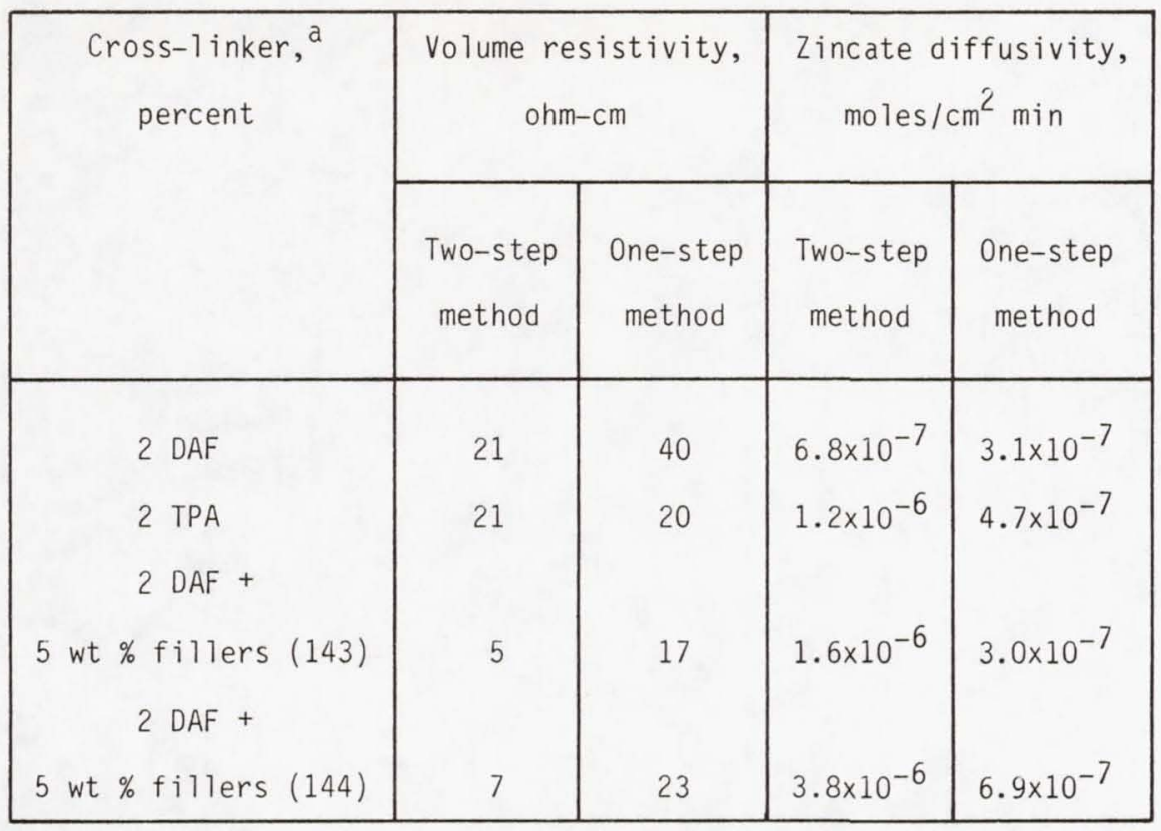

apercentage of theoretical amount required to react with all hydroxyl groups present in PVA.

TABLE IV. - COMPARISON OF POLYVINYL ALCOHOL FILMS WITH VARYING GLYOXYLIC ACID CONTENT

[Sucrose content, 2 wt \%; wet film thickness, 0.014 to $0.018 \mathrm{~cm}$; acid periodate cross-link.]

\begin{tabular}{|c|c|c|c|}
\hline $\begin{array}{c}\text { GOA content } \\
\text { in film, } \\
\text { percent }^{\mathrm{a}}\end{array}$ & $\begin{array}{c}\text { Volume } \\
\text { resistivity, } \\
\text { ohm-cm }\end{array}$ & $\begin{array}{c}\text { Zincate diffusivity, } \\
\text { moles } / \mathrm{cm}^{2} \text { min }\end{array}$ & $\begin{array}{c}\text { Zinc dendrite } \\
\text { penetration } \\
\text { rate, } \\
\mathrm{cm} / \mathrm{min}\end{array}$ \\
\hline 0 & 122 & $2.3 \times 10^{-8}$ & $<4 \times 10^{-5}$ \\
10 & 28 & $3.1 \times 10^{-7}$ & $6 \times 10^{-5}$ \\
35 & 14 & $5.5 \times 10^{-7}$ & $9 \times 10^{-5}$ \\
70 & 12 & $3.9 \times 10^{-6}$ & $2 \times 10^{-4}$ \\
\hline
\end{tabular}

apercentage of theoretical amount required to react with all hydroxyl groups present in PVA. 
TABLE V. - COMPOSITION OF PILOT-PLANT

FILMS $^{\mathrm{a}}$

[Fi]m drying temperature, $350^{\circ} \mathrm{F}$;

line speed, 25 to $30 \mathrm{ft} / \mathrm{min} ;$ dry

film thickness, 1.5 mils.]

\begin{tabular}{|l|c|r|}
\hline \multicolumn{1}{|c|}{ Component } & \multicolumn{1}{|c|}{$\begin{array}{r}\text { Two-step } \\
\text { method }\end{array}$} & $\begin{array}{r}\text { One-step } \\
\text { method }\end{array}$ \\
\cline { 2 - 3 } & \multicolumn{2}{|c|}{ Composition, percent } \\
\hline DAF & 2.3 & 2.0 \\
G0A & 0 & 13.0 \\
Triton X-100 & .7 & .6 \\
Zelec UN & .56 & .5 \\
\hline Film color & Yellow & Clear \\
\hline
\end{tabular}

a Elvanol $71-30$

TABLE VI. - PILOT-PLANT MATERIALS: MEASURED PROPERTIES OF CROSS-LINKED PVA COMPARED WITH THOSE OF CELGARD AND CELLOPHANE

\begin{tabular}{|c|c|c|c|c|c|c|c|}
\hline & $\begin{array}{l}\text { Dry } \\
\text { film } \\
\text { thick- } \\
\text { ness, } \\
\text { cm }\end{array}$ & $\begin{array}{l}\text { Area } \\
\text { resis- } \\
\text { tivity } \\
\text { ohm-cm² }\end{array}$ & $\begin{array}{l}\text { Volume } \\
\text { resis- } \\
\text { tivity, } \\
\text { ohm-cm }\end{array}$ & $\begin{array}{c}\text { Zinc } \\
\text { dendrite } \\
\text { pene- } \\
\text { tration } \\
\text { rate, } \\
\mathrm{cm} / \mathrm{min}\end{array}$ & $\begin{array}{c}\text { Zincate } \\
\text { diffu- } \\
\text { sivity, } \\
\text { moles } / \mathrm{cm}^{2} \text { min }\end{array}$ & $\begin{array}{c}\mathrm{OH} \\
\text { diffusivity, } \\
\text { moles } / \mathrm{cm}^{2} \min \end{array}$ & $\begin{array}{c}\mathrm{H}_{2} \mathrm{O} \\
\text { diffusivity, } \\
\text { moles } / \mathrm{cm}^{2} \text { min }\end{array}$ \\
\hline $\begin{array}{l}\text { PVA (one-step } \\
\text { method) }\end{array}$ & 0.0044 & 0.038 & 8.6 & $2.0 \times 10^{-4}$ & $7.1 \times 10^{-7}$ & $2.6 \times 10^{-4}$ & $4.3 \times 10^{-4}$ \\
\hline $\begin{array}{l}\text { PVA (two-step } \\
\text { method) }\end{array}$ & .0036 & .037 & 10.3 & $1.1 \times 10^{-4}$ & $6.8 \times 10^{-7}$ & $3.0 \times 10^{-4}$ & $3.1 \times 10^{-4}$ \\
\hline Celgard 3401 & .0025 & .078 & 31.0 & $8.5 \times 10^{-4}$ & $29.4 \times 10^{-7}$ & $2.4 \times 10^{-4}$ & $2.5 \times 10^{-4}$ \\
\hline Cellophane & .0025 & .051 & 20.0 & $.4 \times 10^{-4}$ & $22.9 \times 10^{-7}$ & $2.3 \times 10^{-4}$ & \\
\hline
\end{tabular}




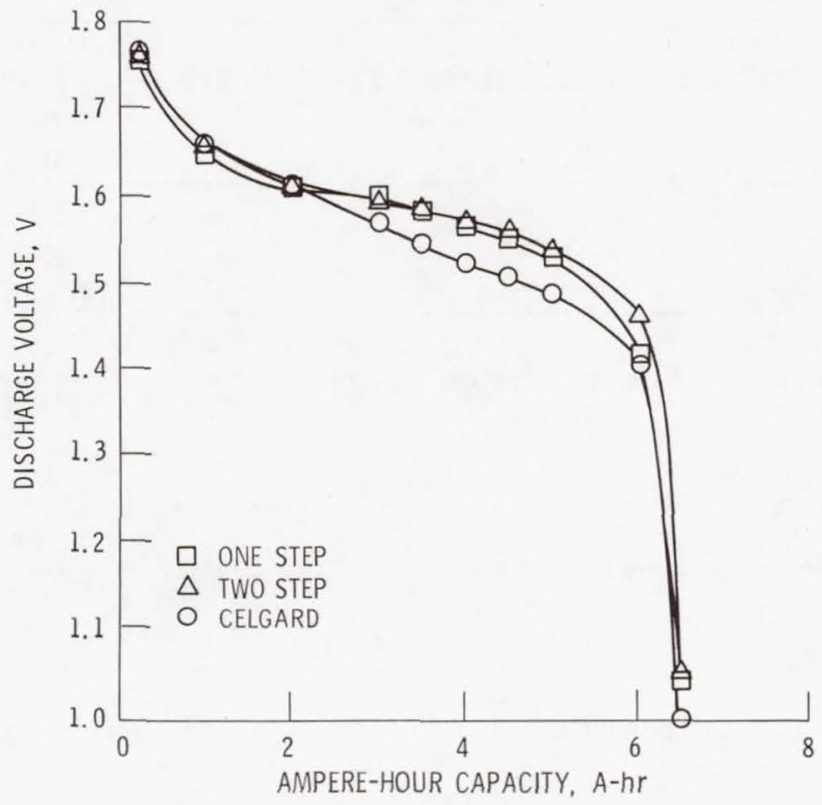

Figure 1. - Comparison of discharge voltage at $\mathrm{C} / 2$ rate - pilotplant-made PVA cross-linked film and Celgard.

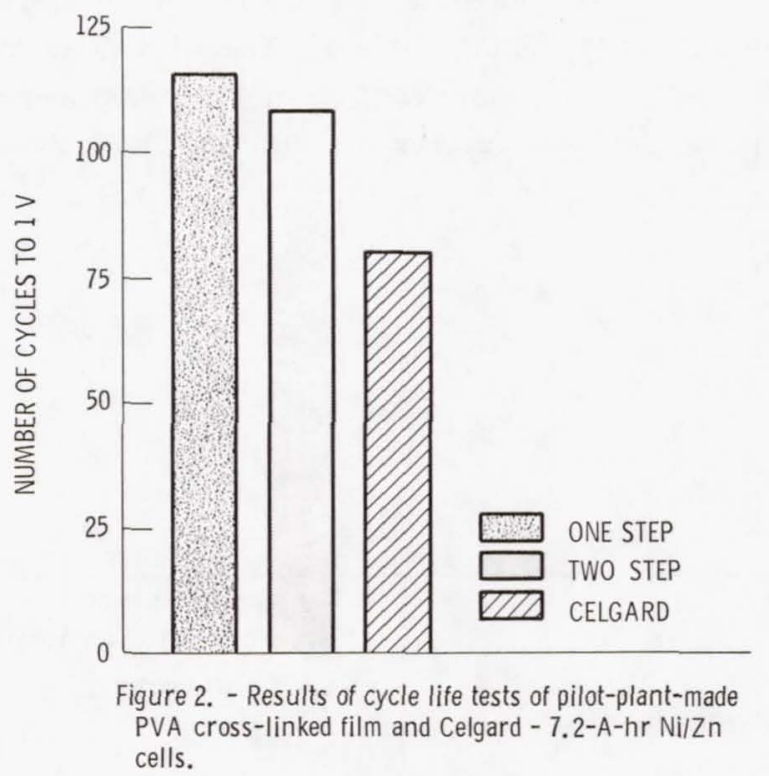




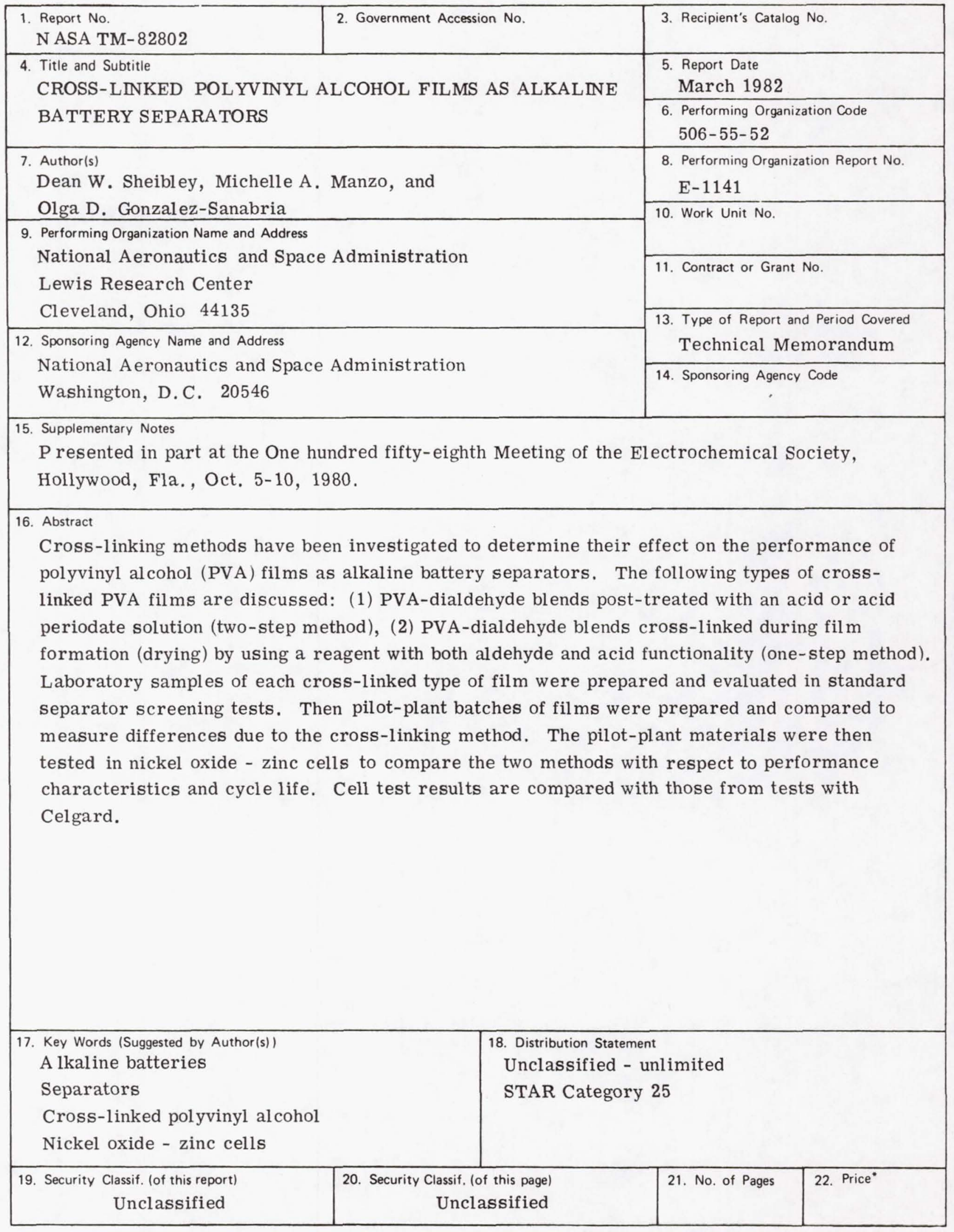

* For sale by the National Technical Information Service, Springfield, Virginia 22161 
National Aeronautics and Space Administration

Washington, D.C.

20546

Official Business

Penalty for Private Use, $\$ 300$
SPECIAL FOURTH CLASS MAIL BOOK
Postage an

National A

Space Adm

NASA-451 